\title{
A SABEDORIA DO CORPO \\ HIPÓTESE DE UM FIO CONDUTOR PARA O DELINEAMENTO COSMOLÓGICO
}

\begin{abstract}
Thiago Gomes da Silva Nunes é graduado em filosofia pela Universidade Estadual da Paraíba (UEPB) e mestre em filosofia pela Universidade Federal da Paraíba (UFPB). Atualmente trabalha como professor substituto da UEPB nos componentes curriculares: Introdução à filosofia, Ética, Filosofia da educação e Filosofia social e política. Como pesquisador trabalha com filosofia moderna e contemporânea no diálogo com as correntes de pensamento antigo, como também com literatura e história antiga.

E-mail: thiagosilva.uepb@gmail.com
\end{abstract}

Resumo: Este artigo apresenta as reflexões do filósofo Friedrich Nietzsche acerca do corpo e o seu saber, naquilo que seria um potencial natural para revelar o caráter unitário da vida como vontade de poder. Neste sentido apresento essa hipótese desde a ideia geral até o seu real desenvolvimento na fase de maturidade dos escritos nietzschianos, mas precisamente na obra Além do bem e do mal de 1886.

\begin{abstract}
This paper presents the reflections of the philosopher Friedrich Nietzsche about the body and your know, in this what would be a natural know to reveal the unitary character of life as will to power. In this sense I present this hypothesis since its general idea until the your actual development at the stage of maturity of the nietzschean writings, more precisely in the work Beyond Good and Evil of 1886.
\end{abstract}

A obra do filósofo Friedrich Nietzsche $(1844$ - 1900) é marcada pela tentativa de fundamentar a especulação cosmológica da vontade de poder (Der Wille zur Macht), tese que receberia posteriormente do conceito eterno retorno (Ewige Wiederkunft) o seu complemento estrutural. A vontade de poder junto do eterno retorno passariam a designar desde Assim falou Zaratustra (1883 - 1887), passando pela A gaia ciência (1882 - 1886), Além do bem e do mal (1886), Crepúsculo dos ídolos (1888), Ecce Homo (1888) e $O$ anticristo (1888), além dos fragmentos póstumos datados do período de maturidade (1885 - 1889), uma concepção de cosmos inspirada nas intuições espaçotemporais helênicas, pautando-se no vislumbramento de uma vida cíclica em um eterno conflito entre as diversas forças da natureza. A mais enfática dessas representações foi dada pela filosofia de Heráclito de Éfeso (535 - 475 a.C), esse que parece ser a perfeita manifestação do pensamento filosófico porvir, mas ainda enraizado na tradicional intuição cosmológica de uma Physis; a influência desse pensador seria determinante para a formação de Nietzsche.

Neste percurso a vontade de poder e o eterno retorno passaram a compor o cerne do projeto filosófico nietzschiano que tinha em vista a suplantação da metafísica ocidental, o que só poderia ser efetuado a partir do vislumbramento arcaico de um mundo envolvido por um afeto primordial. Ao tentar legitimar esta especulação cosmológica, Nietzsche veio a considerar a possibilidade de se obter um ponto de partida epistemológico para o entendimento do cosmos. A primeira menção à tese do corpo como grande razão foi apresentada em Assim falou Zaratustra, mas no decorrer da obra nietzschiana de maturidade ele retomaria sucessivamente essa referência. Ao contrário

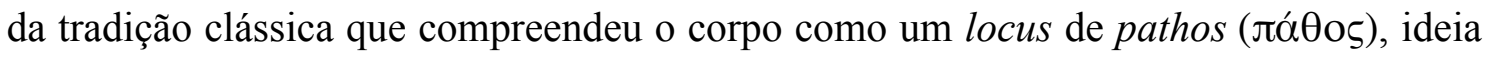
que emergiu com o platonismo, Nietzsche buscará no âmbito das paixões o ponto partida para confrontar a metafísica ocidental e validar sua concepção de vida.

A tradição que ele tem como alvo pode ser compreendida como "um determinado modo de ver o princípio a partir da separação do real em dois mundos ou dois níveis, o que, segundo Nietzsche, teria acontecido a partir da filosofia de Platão" (CORDEIRO, 2010, p. 54). Essa tradição seria o grande fenômeno de depreciação dos afetos, instintos e pulsões que caracterizam a condição corporal, como também de todas as possibilidades que o corpo sempre ofereceu, e da vida como um todo. Ao contrário da metafísica platônica, a hipótese nietzschiana parte do entendimento de que não há qualquer 
distinção entre homem e cosmos, e desta forma ele cogita que um fenômeno tão íntimo e real como o corpo pode vir a auxiliar o conhecimento/reconhecimento da vida.

Para confrontar a tradição, Nietzsche olha por detrás do platonismo, para uma época onde não havia qualquer distinção entre homem e natureza, um período em que o ser humano possuía uma relação muito mais natural, afetiva e efetiva com a própria existência. Nietzsche tem em vista a chamada a tradição arcaica, expressa, sobretudo, pela literatura pré-platônica, um exemplo memorável desse modo de ver e viver que não se apartava da condição corporal, mas que assumia o teor corpóreo da existência como o único caminho a ser trilhado pelo homem. Na literatura arcaica os afetos, paixões e intuições não eram fenômenos a serem combatidos ou negados, mas sim a própria vida a falar como se os deuses estivessem a cantar.

Para adentrar a hipótese nietzschiana devemos antes ter clareza que o elemento que perpassa a sua reflexão é um tipo distinto de percepção inspirada na literatura arcaica, mas em última instância intermediada ou referenciada pelo pensamento Arthur Schopenhauer $(1888$ - 1860). Seja como for, a filosofia nietzschiana toma como base de raciocínio isto que seria denominado por Werner Jaeger $(1888$ - 1961) de cosmovisão orgânica, um traço percepção característico do tipo humano que antecedeu a tradição platônica, posto que ainda não havia qualquer distinção entre homem e mundo. Sendo assim, encontramos uma das mais significativas passagens de Nietzsche em relação à hipótese do corpo como grande razão na obra Além do bem e do mal. O aforismo 36 é, provavelmente, o mais completo em relação à hipótese, visto que o trecho envolve tanto os elementos que já haviam sido apresentadas em Assim falou Zaratustra, mas vão além, pois a passagem data da fase de maior maturidade de Nietzsche, os seus últimos anos de lucidez.

Mas antes de adentrar esta discussão, vejamos algumas das refutações de Nietzsche em relação às correntes de pensamento que viriam a marcar a modernidade junto de suas concepções de homem e natureza. Primeiramente ele critica a postura daqueles que clamavam pela necessidade de viver "conforme a natureza" (NIETZSCHE. 2005, p. 14) sem saber de fato do que falavam. Nietzsche se referia ao bom selvagem de JeanJacques Rousseau (1712 - 1778) ou mesmo à antiga doutrina estoica. Os modelos de homem e natureza esboçados pelas tradições de pensamento moderno, especialmente o Iluminismo e o Romantismo, na verdade refletiriam a concepção de existência que tanto desconheciam, posto que elas estariam envolvidas por ideais metafísicos que ludibriaram e movimentaram gerações inteiras em prol de poder.

Desta forma Nietzsche questionará como poderiam fazê-lo - no caso, os adeptos das tradições românticas - viver conforme "este" estado de natureza se viver "não é querer ser diverso dessa natureza? Viver é avaliar, preferir, ser injusto, ser limitado, ser diferente?" (NIETZSCHE, 2005, p. 14.). Os ideais de natureza e naturalidade evocados pelas correntes românticas na verdade trilhavam o caminho de uma inocência destituída de qualquer realidade, porém aí estava a vida a trabalhar no seu jogo ficcional, posto que ela nada mais seria que vontade de poder. Percebe-se aí que a concepção de homem e mundo delineada pelo pensamento nietzschiano procurará enfatizar o desejo de diferenciação, a luta pela distinção e o âmbito a-moral do cosmos, tendo em vista que a vida, e portanto o homem são na sua essência pulsões desejosas por poder.

Da mesma forma o mecanicismo receberia uma crítica ferrenha, e é para destacar a falha do conhecimento científico que Nietzsche afirma que qualquer interpretação de mundo que parta de uma percepção distinta da mecanicista, ou seja, com intenções e arte interpretativa totalmente opostas, por mais que tenha em vista os mesmos fenômenos destacados pelo próprio mecanicismo e ainda que seja movida pelas melhores intenções ao fim, sempre será uma percepção de mundo limitada e de certa 
forma esgotada do ser. Isso porque toda e qualquer interpretação do mundo acaba por reafirmar aspectos de fatalidade e cálculo do curso da vida, isto é, o conhecimento científico sempre esbarra e trabalha com uma série de dados metafóricos que não deixam ser simples ficções, por mais que isso não implique em um total apartamento da existência.

Nietzsche atesta que o cosmos "tem um curso 'necessário' e 'calculável', mas não porque nele vigoram leis, e sim porque faltam absolutamente as leis, e cada poder tira, a cada instante, suas últimas consequências" (NIETZSCHE, 2005, p. 27). Os homens só podem ter acesso aos resultados do grande ciclo ficcional da vida, e desta maneira podese pressupor sequências normativas do processo de superação do viver, sabe-se que a fatalidade da existência é caos por todos os lados, mas nunca poder-se-ia obter um dado imutável no sentido de uma lei física.

Percebe-se que Nietzsche retoma algumas das figuras de representação da tradição filosófica pela própria impossibilidade de se expressar um juízo se não pelos signos que herdara. Esse fato lhe era tão consciente que ele nos deixa um tipo de ressalve ao dizer que os "conceitos filosóficos individuais não são algo fortuito e que se desenvolva por si, mas crescem em relação e em parentesco um com o outro; embora surjam de modo aparentemente repentino [...] não deixam de pertencer a um sistema" (NIETZSCHE, 2005 , p. 24). Não é de se espantar que a especulação cosmológica nietzschiana acabe por reafirmar e reproduzir algumas dos aspectos metodológicos da tradição que criticava, pois no fim das contas ela é fruto do próprio esclarecimento filosófico.

Assumindo que a condição da vida é vontade de poder, e que sendo próprio da vontade a plena atuação sobre mais vontade - vida que atua sobre vida - sua preocupação visa formular uma interpretação que, ao mesmo tempo que consiga se despir de toda a gama de resquícios antropomórficos de uma tradição moribunda, também possa corresponder ao dinamismo, força e complexidade do real. $\mathrm{O}$ aforismo 36 destaca que a sabedoria do corpo pode ser o ponto de partida para o conhecimento da vida, tendo em vista o mundo dos desejos, afetos e pulsões até o momento desprezadas pela tradição metafísica. Para Nietzsche nada além das paixões e afetos pode ser tomado como realidade, afinal de contas, o corpo é a primeira e mais acessível manifestação do real, o que implica dizer que todo e qualquer conhecimento é uma manifestação perspectivista de vida marcada pela visceralidade corporal. Vejamos, assim, o aforismo 36:

Supondo que nada seja "dado" como real, exceto nosso mundo de desejos e paixões, e que não possamos descer ou subir a nenhuma outra "realidade", exceto à realidade de nossos impulsos entre si - : não é lícito fazer a tentativa e colocar a questão de se isso que é dado [as paixões e afetos] não bastaria para compreender, a partir do que lhe é igual, também o chamado mundo mecânico (ou "material")? Quero dizer, não como uma ilusão, uma "aparência", uma "representação" (no sentido de Barkley e Schopenhauer), mas como da mesma ordem de realidade que têm nossos afetos, - como uma forma mais primitiva do mundo dos afetos, na qual ainda esteja encerrado em poderosa unidade tudo o que então se ramifica e se configura no processo orgânico (e também se atenua e se debilita, como é razoável), como uma espécie de vida instintiva, em que todas as funções orgânicas, como auto-regulação, assimilação, nutrição, eliminação, metabolismo, se acham sinteticamente ligadas umas às outras - como uma forma prévia da vida? - Afinal, não é apenas lícito fazer esta tentativa: é algo imposto pela consciência do método. Não admitir várias espécies de causalidade enquanto não se leva ao limite extremo ( - até ao absurdo, diria mesmo) a tentativa de se contentar com uma só: eis uma moral do método, à qual niguém se pode subtrair hoje; ela se dá "por definição", como diria um matemático. A questão é, afinal, se reconhecemos a vontade realmente como atuante, se acreditamos na causalidade da vontade: assim ocorrendo - e no fundo a crença nisso é justamente a nossa crença na causalidade mesma -, temos então que fazer a tentativa de hipoteticamente ver a causalidade da vontade como a única. "Vontade", é claro, só pode atuar sobre "vontade" - e não sobre "matéria" (sobre 
"nervos", por exemplo -): em suma, é preciso arriscar a hipótese de que em toda parte onde se reconhecem "efeitos", vontade atua sobre vontade - e de que todo acontecer mecânico, na medida em que nele age uma força, é justamente força de vontade, efeito da vontade. - a vontade de poder, como é minha tese-; supondo que se pudesse reconduzir todas as funções orgânicas a essa vontade de poder, e nela se encontrasse também a solução para o problema da geração e nutrição - é um só problema -, então se obteria o direito de definir toda força atuante, inequivocamente, como vontade de poder. (NIETZSCHE, 2005, p. 39 - 40)

A isto que é dado ao homem, referindo-se aos afetos e instintos próprios à condição corpórea, Nietzsche toma como a base de qualquer avaliação que pretenda compreender o cosmos. Tudo, para aquém ou além dos afetos e instintos, poderá ser resumido em mais uma entre as tantas formas de representação da pulsão de ficcionalidade da vida. Enquanto vontade de poder, o corpo é a vida propriamente dita na sua plenitude para ser, ele é, assim, a "grande razão, uma multiplicidade com um só sentido, uma guerra e uma paz" (NIETZSCHE, 2011, p. 34 - 35). A tão estimada razão da tradição acaba por ser compreendida como mais uma entre as tantas pulsões de vida manifestas, o que levaria a discussão daquilo que caracteriza uma das formas da decadência apresentadas pela obra nietzschiana: a tirania de um instinto ou uma pulsão de vida sobre os demais, aquilo que compreendeu como um tipo de nivelamento e castração do poder da vida.

A hipótese nietzschiana é essencialmente antidualista, e portanto é contra qualquer postulação de princípios ou realidades inconciliáveis, especialmente no caso daquela proposta por René Descartes $(1596$ - 1550) na clássica distinção entre substâncias corpóreas e espirituais. Esse gênero de diferenciação não se iniciou, obviamente, com Descartes, contudo foi ele quem deu voz a uma nova e imponente manifestação da metafísica ocidental, e que viria a se converter na ciência moderna.

Para além da uma simples especulação filosófica, a indissociabilidade entre a unidade corpo-mente se torna ainda mais enfática ao se ter em vista o seu grau de realidade. Neste sentido trago à discussão as palavras de Antônio Damásio (1944), presentes na obra $O$ erro de Descartes de 1994. O estudo apresentado por Damásio argumenta contra o tradicional sistema de pensamento dualista, baseando-se em resultados obtidos numa longa e precisa observação de casos clínicos que apresentaram problemas de interação entre o corpo e a mente.

É assim que Damásio demonstra como esta velha oposição é totalmente inconcebível, primeiramente, porque a mente, como nós a (des)conhecemos, não seria o que é sem a interação pré-histórica mantida entre corpo e cérebro, em segundo porque o corpo e a máquina neural constituem uma unidade indissociável por meio de circuitos reguladores bioquímicos e neurológicos. Tudo isso indica que o organismo se comunica com o ambiente como uma unidade interativa, e portanto "as operações fisiológicas que denominamos por mente derivam desse conjunto estrutural e funcional e não apenas do cérebro" (DAMÁSIO, 1996, p. 17).

As considerações de Damásio enfatizam o grau de realidade da hipótese nietzschiana, visto que o corpo oferece mais que um simples sustento e modulação perceptiva à atividade mental, mas ele é justamente o "tema básico para as representações cerebrais" (DAMÁSIO, 1996, p. 17). Os dados apresentados por Damásio demonstraram como um indivíduo que venha a sofrer um dano mínimo na estrutura responsável pelo processamento da capacidade sensitivo-afetiva (o lóbulo frontal), por mais que mantenha as capacidades racionais intactas, desenvolverá necessariamente problemas que inviabilizam a conduta ética a curto e longo prazo. Isso significa dizer que a estrutura perceptivo-afetiva oferecida pela unidade mente-corpo não é apenas um meio de se conhecer e lidar com a vida, mas ela é o único meio, uma vez que aquilo que 
chamamos de razão depende fisiologicamente da perfeita interação com o canal sensitivo e afetivo oferecido pelo corpo.

$* * *$

A estrutura cognitiva sempre estará limitada por sua condição perspectivista, dado que testemunha como o estado corporal é efetivamente presente em todas as atividades da vida diária, seja nas mais simples e singulares, seja na mais originária e complexa reflexão racional. No entanto Nietzsche deixa de lado as limitações da percepção humana para destacar aquilo que há de essencial na vida como vontade de poder: a atuação da vontade sobre a própria vontade, o jogo de comando e obediência do ser, a condição de atuação do vivente. Se nada pode ser considerado real, no sentido do saber cristalizado e imutável apresentado pela tradição filosófica, uma vez que o mundo é um eterno devir destituído de qualquer significado ou sentido a priori, as paixões, afetos e instintos são a própria unidade elementar a falar e valorar através da finitude humana.

Não existiria, assim, qualquer reminiscência platônica ou desvendamento de fatos por detrás das saias de uma natureza acanhada, pois o significado de uma coisa sempre será uma prescrição da vida no seu ciclo de comando e obediência. Isso significa dizer que a vida deriva de um ciclo indissolúvel de instituição de valor sob o viés do espelho humano, e os instintos, afetos e paixões são a própria manifestação da vontade de poder na sua atuação. O homem, como um ser visceralmente perpassado por afetos e paixões, é um ser de atuação, o que na verdade indica que ele é um ser em estado de plena valoração. $\mathrm{O}$ substrato afetivo e instintivo da vida é aquilo que dita o que deve ser instituindo, com isso o valor e o sentido de uma coisa para a face de vida que valora sempre fazem referência a uma dada condição existencial, nesse caso, a manifestação corpórea que prescreve o valor. Por isso mesmo Nietzsche questiona no aforismo se "isto" que dita o que é, ou seja, que comanda, cria e institui o valor não pode ser tomado como a base para o entendimento daquilo que "lhe é igual"?

Como fora exposto no começo, no pensamento nietzschiano não há qualquer distinção significativa entre homem e mundo, muito menos entre atividade cognitiva e corpórea, o que tem por consequência a indissociabilidade entre as instâncias: mente e corpo ou homem e natureza. Nietzsche compreendia que tudo na existência era vontade de poder em plena atuação, e a multiplicidade de faces da vida diz respeito ao necessário cíclo de superação de um cosmos que tem de guerrear consigo mesmo para que o devir continue no seu curso cíclico; a guerra seria, assim, o princípio motor do cosmos. Desta maneira o próprio instinto de conhecimento pode ser compreendido como uma forma atuação da vida, uma manifestação da vontade de poder; portanto pensar, interpretar, representar e valorar são formas de atuação da vida sobre a própria vida, configurações distintas da manifestação corporal.

O conceito instinto de conhecimento parece surgir como uma fórmula que dá sentido às noções de interpretação e representação dentro do pensamento nietzschiano. Ele seria uma expressão subsequente ao primeiro comando da vontade de poder, parte da atuação instintivo-afetiva implícita a toda condição corporal, aquilo que dita os sentidos e os fins a serem buscados pelo esclarecimento. Mas por mais que o conhecimento seja uma manifestação derivada do primeiro comando instintivo e afetivo, ele não se distingue essencialmente da vontade de poder, na medida que o primeiro fenômeno é apenas uma expressão posterior do segundo, posto que os dois compõe uma única e mesma realidade, a vida. $\mathrm{O}$ conhecimento humano seria, de maneira geral, mais uma entre as tantas manifestações da vida, o que pressupõe dizer que interpretar e representar são atividades típicas da pulsão de vida que procura persuadir, convencer, expandir-se e dominar. 
Raciocínio semelhante teria sido apresentado por Nietzsche no período de atividade docente nos anos de 1869 a 1879, como testemunha a pequena coletânea de escritos de juventude Da retórica. Nesta época ele já compreendia como a linguagem é uma atividade puramente metafórica, derivada de um processo de apreensão sensorial limitado e condicionado pela condição corporal, isto é, pelo estado fisiológico. Nesta época Nietzsche compreendia que em vez de assimilar as coisas como elas são, o homem na verdade apreende uma marca sensorial (Merkmal), ou seja, um fenômeno de segundo plano.

Essa ideia levara Nietzsche a cogitar um instinto retórico inerente à estruturação linguística, posto que, sendo a linguagem uma ordenação metafórica determinada pelas condições fisiológicas e ambientais do ser que interpreta e representa, aquilo que seria futuramente compreendido como caráter perspectivístico, também lhe é próprio a tentativa de persuadir e impor uma determinada percepção do ser, uma doxa. Nietzsche conclui que a retórica "estava já em acto, como meios de uma arte inconsciente, na linguagem e no seu devir, e mesmo que a retórica é um aperfeiçoamento (Fortbildung) dos artificios já presentes na linguagem" (NIETZSCHE, 1995, p. 44). Essa tese acarreta na negação de qualquer imparcialidade atribuída à linguagem, dado que o curso de seu desenvolvimento resulta de um longo processo de aperfeiçoamento dessa arte retórica inerente à constituição humana.

Quando retornamos à fase de maturidade dos escritos nietzschianos percebemos que a tese de juventude não desapareceria por completo, uma vez que ela evoluíra justamente para a fórmula do instinto de conhecimento. Desde a juventude Nietzsche compreendia que as atividades da interpretação e representação não nutrem teor algum de imparcialidade, mas são edificações imagéticas condicionadas pelas forças da vida. Este movimento só pode ser compreendido como curso de exposição gratuita do viver, livre de qualquer significação a priori, livre de qualquer orientação que não seja a simples exposição do existir, instituir, realizar, fazer-se visível, crescer, impor e intensificar a própria condição de vontade de poder.

Ele compreende, assim, que interpretar e representar são atividades típicas de uma categoria de juízo, ou ainda de um instinto ou pulsão de conhecimento que fatalmente procura impor sua perspectiva diante da existência, instinto esse que reflete a necessidade/fatalidade de uma manifestação de vida. A instituição de valor e sentido visam não só conservar um expressão de vida humana, mas sobretudo garantir a sua expansão e dominação em meio às demais. É por isso Nietzsche declara que conhecer "é criar, seu criar é legislar, sua vontade de verdade é - vontade de poder" (NIETZSCHE, 2005, p. 106).

O valor atribuído pelo instinto de conhecimento significa, no limite, utilidade, logo algo desejável para a manutenção e potencialização do estado corporal que interpreta, representa e institui o valor. Em síntese, representação e interpretação são organizações de mundo "segundo o perspectivismo dos valores pelos quais um ser exprime o seu engajamento existencial" (GRANIER, 2011, p. 66). Em si os valores resultam de determinadas perspectivas de utilidade que visam o sustento e o incremento das configurações de fortalecimento, expansão e domínio do homem. Não existe qualquer valor fora do grau de poder, tendo em conta que a vida é um eterno anseio por potencialização do viver. Dessa maneira os valores instituídos pelo instinto de conhecimento, isto é, as atividades da interpretação e representação, serão sempre reflexos da vida que valora na sua força de manifestação, e que significa, antes de tudo, uma manifestação corporal.

Deste modo Nietzsche considera que o instinto de conhecimento é um fenômeno nada imparcial, já que não existe interpretação que não carregue consigo os valores que são 
próprios à conservação e fortalecimento de um estado corpóreo. Os valores sempre farão referência a uma forma de existência, sempre espelharão um tipo de juízo, sempre dirão respeito à perspectiva de manutenção e crescimento da vida que valora. Conhecer é, portanto, instituir valor, e tais valores denunciam como o conhecimento é uma manifestação corpórea e perspectivista.

Entender que a edificação do conhecimento é um processo limitado e além de tudo marcado pela fisiologia humana, logo, que o homem é incapaz de obter um dado real acerca do ser, no sentido de um elemento cristalizado e imutável, demonstra como as considerações nietzschianas de juventude mantém-se próximas das de maturidade. Mas isso se dá principalmente quando Nietzsche passa a compreender que o teor retórico do instinto de conhecimento na verdade é manifestação de vida que luta por dominação e envolvimento do real, na busca pelo acréscimo de poder.

Mas agora a vida não poderia mais ser compreendida como um juízo relativo destituído de materialidade, nem como ciclo de causalidades díspares derivadas da relação previsível entre leis imutáveis. A menção ao método que se impõe à consciência não é mais aquele advindo da tradição de pensamento ocidental, mas ele parte do reconhecimento de uma única e mesma causalidade por detrás de toda e qualquer manifestação da vida, ele é o limite da cosmologia nietzschiana: a "redução de todas as funções orgânicas fundamentais à vontade de poder" (NIETZSCHE, 2013, p. 8). Admitir a plenitude de atuação da vida é compreender como todo vivente está imerso em um jogo ficcional, dado que evoca com mais força a impossibilidade de se ausentar do processo de representação do ser. Mas esse reconhecimento também possibilita ver que a diversidade de atuações do viver pode ser compreendida a partir de sua identidade, como decorrência de uma única pulsão instintiva que tudo determina.

Isto posto, o corpo como espaço de desvelamento dos afetos e instintos é a ferramenta postulada por Nietzsche para a revelação do que há de identitário na diversidade de formas do cosmos, visto que a origem destas predisposições revela uma forma prévia e primitiva de instinto a qual todas as outras fazem referência. Contudo isto só é possível atentando para o que há de identitário nos afetos e instintos, ou seja, o modo como se manifestam, mesmo que na sua diversidade de formas, instabilidade, dinamismo e contraste, mas principalmente no seu ciclo tirânico de vida. O arcabouço instintivoafetivo que perfaz a existência corpórea pode revelar, ao menos parcialmente, a identidade deste que seria um afeto primitivo, aquilo em que tudo estaria "encerrado em poderosa unidade", a fonte em que toda vida se ramifica e se configura no processo orgânico.

Infelizmente a solução para o problema cosmológico não estava simplesmente dada. Nietzsche compreende que é essencial partir do corpo, utilizando-o como fio condutor, já que ele é um fenômeno rico em possibilidades e que permite uma observação clara do que seja a vida. A mesma ideia havia sido expressa no discurso Dos desprezadores do corpo de Assim falou Zaratustra, onde ele afirma que "Por trás dos teus pensamentos e sentimentos, irmãos, há um poderoso soberano, um sábio desconhecido - ele se chama Si-mesmo. Em teu corpo habita ele, teu corpo é ele" (NIETZSCHE, 2011, p. 35). O Simesmo destacado por Zaratustra é o quantum identitário de vida em um dado corpo, aquilo que possibilita identificar o vivente como parte do cosmos.

Mesmo dentro de um determinado estado corporal, ainda há um desmembramento da vontade de poder em vigor em inúmeras formas particulares de vontade que lutam pela supremacia do espaço em questão, aquilo que Nietzsche denominou por força. Esse conceito é, provavelmente, a última caracterização significativa apresentada pela obra nietzschiana, mas a maior parte dos escritos que fazem referência à ideia são fragmentos póstumos datados dos últimos anos de produção. Isso quer dizer que o corpo, com todas 
as suas faces de deslevamento instintivas e afetivas, ainda é um verdadeiro recinto de combate entre um conjunto inumerável de pulsões em constante vir a ser. O corpo é, pois, um verdadeiro espaço de contradições movido pelo jogo de forças da vida.

Entretanto um fragmento póstumo datado de 1885 problematizará um pouco mais a questão, dado que nele Nietzsche atesta um elemento antes subtendido. Ele diz: "Se as coisas são desconhecidas, então o homem também o é"(NIETZSCHE, 2013, p. 5), algo que faz sentido se observarmos que as limitações perspectivistas admitidas anteriormente por seu raciocínio. Compreender que a vida é um verbo enigmático marcado antes de tudo pelo caos do vir a ser, significa dizer que o homem, como parte constituinte e indissociável do cosmos, também é um contínuo e eterno mistério. Fica então a questão: como pode o corpo ser a ferramenta de desvelamento da vida se o homem, por si, constitui-se como um berço de contradições e mistério, ou melhor, um verdadeiro locus fomentador de ficções?

É preciso atentar para o fato de que o Nietzsche busca conceber um novo modos operandi de pensamento que consiga suplantar o derivativo de primeira ordem da tradição metafísica: a lógica. Em síntese, o pensamento lógico é aquele que está de acordo com um determinado encadeamento funcional de reflexão, o que na tradição metafísica significou pensar racionalmente, e em última instância pensar com a coerência correta para se obter a verdade, ou seja, aquilo que muitos consideraram como o bem. A sabedoria evocada por Nietzsche é aquela que fora renegada por toda uma tradição cultuadora da racionalidade lógica, essa que viria negar o próprio corpo ao tomá-lo como âmbito de pathos. Com isso a lógica se tornou parte indissociável da tradição filosófica, mas também do pensamento cotidiano.

Seja como for, a hipótese do corpo como grande razão busca inverter o método da tradição, sua lógica, afinal de contas, "faltam ao "lógico" a indicação e o peso do verdadeiro", o que significa dizer que aquilo que "é "lógico" não precisa ser verdadeiro" (HEIDEGGER, 2010, p. 126). Nietzsche tinha em vista justamente demonstrar como a lógica não é nenhuma instância ou fonte para se obter a verdade, muito pelo contrário. Desde Platão a razão se apresentou como uma deformação do saber-viver arcaico, pois é um tipo de conhecimento que não consegue lidar com as contradições e o vir a ser da vida, e por isso o mundo das paixões fora veementemente negado pela metafísica tradicional. Afirmar que um raciocínio é lógico significa dizer, geralmente, que se desconhece inteiramente a coisa que se atribui o juízo, justamente porque a lógica é um tipo específico de encadeamento reflexivo que não é necessariamente verdadeiro, uma vez que diz respeito muito mais ao ser que raciocina, e não à coisa pensada.

$\mathrm{O}$ fato é que as coisas exteriores ao pensamento racional possuem a sua própria lógica de ser, e desta forma o pensar correto aproxima-se mais daquele que procura refletir a coisa a partir de sua própria lógica. Nada obstante, com a admissão de um cosmos marcado por caos e vir a ser, é-se levado a perguntar: 'como se pode aplicar o pensamento nas coisas sem antes saber ao certo sobre as coisas e a sua "lógica"?' (HEIDEGGER, 2010, p. 201). Um dos possíveis caminhos apresentados por Nietzsche - a sabedoria do corpo - tem de lidar com um aspecto paradoxal: o corpo é o fenômeno mais claro e a grande razão, mas ele também é um berço de contradições e um eterno mistério. Contudo a identificação da aparente contradição da hipótese na verdade é mais um reflexo do encadeamento lógico que nos é constitutivo, e que por isso não consegue lidar com as contradições implícitas à própria vida, postuladas por Nietzsche, aqui, como sendo constitutivas da lógica caótica da vontade de poder.

As considerações que dizem respeito ao corpo como grande razão e ao mesmo tempo como fonte de contradições na verdade buscam destacar que o homem é um espaço de possibilidades, essas que não se limitam à simples dualidade aqui destacada. Portanto a 
hipótese nietzschiana busca repensar a condição corpórea e o papel até o momento atribuído aos instintos e afetos na tradição. Como vimos, a condição de impenetrabilidade da vida é definida por seu caráter caótico: a suma necessidade de vir a ser acentuada pela instabilidade e mutabilidade relacional do cosmos, o fluxo implícito de todo viver. Da mesma forma o homem não poderia ser um ente cristalizado no tempo e no espaço pelo simples motivo de que ele é uma manifestação de vida em fluxo.

Tal como a vida na sua múltipla unidade, o homem sempre será um ente essencialmente desconhecido, resultado derivado de sua imersão no jogo de forças da vida. Contudo isso não tem por implicação que o ser humano é uma síntese de incoerência e delírio, muito pelo contrário. Ao destacar duas percepções superficialmente opostas do que seja este homem-corpo, Nietzsche reinterpreta essa ideia ao expor a potencialidade para ser que vigora no âmbito afetivo e instintivo, e a partir daí o caráter múltiplo do ser humano será tido como uma imensa concentração de potencialidade, talvez a maior que já nos foi conhecida. Porém o homem moderno, o primeiro ente visado pela crítica nietzschiana, é caracterizado pelo enfraquecimento e a degeneração desse poder criativo. Repensar o homem-corpo a partir de sua condição contraditória - a multiplicidade de forças que compõe - significa destacar a potencialidade criativa que lhe é constitutiva, aquilo que o impulsiona para além de qualquer rótulo identitário. Desta forma o âmbito dos afetos e paixões, muito mais que um simples espaço de engano e incoerência desprovido de qualquer razão, é, primeiramente, o tema elementar oferecido ao processo cognitivo e representativo do mundo. Esse raciocínio mantém relativa proximidade com a lógica idealista ao afirmar que o mundo objetivo é uma modelação predominantemente marcada pelas limitações da percepção humana, e portanto assinalado pelas determinações físiológicas do ser que pensa e reflete.

Mas é ao partir daquilo que conhecemos que se torna possível estruturar uma percepção menor do que desconhecemos, talvez como um tipo de intuição norteadora para a reflexão racional. Sob os termos nietzschianos podemos dizer que o corpo é aquilo que nega terminantemente o não ser, já que "tudo quanto percebemos é alguma coisas, e esse algo positivo é uma experiência de ser, e não uma experiência de nada, porque se fôsse de nada, como seria alguma coisa? Como poderia ser uma experiência de não-ser o que já é alguma coisa?" (SANTOS, 1959, p. 21). O corpo é uma ferramenta contra qualquer tipo de ceticismo, ou ainda qualquer interpretação que procure enquadrar o pensamento nietzschiano na lógica relativista ou subjetivista, que seria o caso de Gianni Vattimo (1936) e Jürgen Habermas (1929).

No entanto Nietzsche não se aprofundaria significativamente na análise dessa ideia, por mais que continuasse a repensar a condição de potencialidade humana, sempre frisando repetidamente os dados da hipótese corporal. O corpo auxilia no conhecimento cosmológico a partir do momento que passamos a compreendê-lo como espaço de desvelamento das paixões, ou seja, como âmbito de eclosão das pulsões instintivas e afetivas. A partir daí pode-se pressupor que o corpo ressalta uma série aspectos destacados pela obra nietzschiana como um todo, ao exemplo [1] da fatalidade da vida como a condição de subordinação do vivente à vontade elementar; [2] a impossibilidade de se pensar a fundo a ideia de indivíduo posto que esse nada mais seria que uma ficção; [3] a inseparabilidade entre as instâncias mente-corpo e homem-mundo; [4] o instinto de conhecimento como manifestação de vida em atuação.

Mas antes de qualquer coisa, o corpo é aquilo que revela o quanto o homem é, propriamente, vontade de poder, ou seja: o'homem como uma pluralidade de "vontades de poder": cada uma com uma pluralidade de meios de expressão e formas'(NIETZSCHE, 2013, p. 15). O fenômeno corpo é o que evidencia a condição de 
possibilidade criativa do homem, revelando-o como manifestação plurissignificativa de vida no jogo criativo e reconfigurador. $\mathrm{O}$ corpo enfatiza como o homem é apenas o resultado de um jogo de forças em um eterno combate por poder, o que na verdade faz referência ao processo cosmológico de superação de si mesmo. Com isso ele pode ser um elemento de destaque ao auxiliar o delineamento cosmológico com o desvelamento de sua própria identidade.

\section{REFERÊNCIAS BIBLIOGRÁFICAS}

CORDEIRO, Robson Costa. Nietzsche e a vontade de poder como arte: uma leitura a partir de Heidegger. João Pessoa - PB: Editora universitária/UFPB, 2010.

DAMASIO, António R. O erro de Descartes: emoção, razão e cérebro humano. Tradução de Dora Vicente e Georgina Segurado. São Paulo - SP: Editora Schwarcz LTDA, 1996.

DESCARTES, René. Meditações. Tradução de J. Guinsbung e Bento Prado Júnior. São Paulo - SP: Nova cultural, 1973.

GRANIER, Jean. Nietzsche. Tradução: Denise Boatman. PortoAlegre - RS: L\&PM POCKET, 2011.

HABERMAS, Jügen. Discurso filosófico da modernidade. Tradução: Luiz Sérgio Repa e Rodnei Nascimento. São Paulo - SP: Martins Fontes, 2002.

HEIDEGGER, Martin. Lógica e doutrina heraclítica do logosin Heráclito. Tradução: Márcia Sá Cavalcante Schuback. Rio de Janeiro - RJ: Ed. Relumedumara, 1998.

ISIDRO PEREIRA, S.J. Dicionário grego-português e português-grego. Lisboa: $5^{\text {a }}$ Ed. Livraria apostolado da imprensa, 1976.

JAEGER, Werner. Paidéia: A formação do Homem Grego. Tradução: Artur M. Parreira. São Paulo - SP: $3^{\text {a }}$ Ed. Martins Fontes, 1994.

NIETZSCHE, Friedrich. A gaia ciência. Tradução: Paulo César de Souza. São Paulo SP: Ed. Companhia das letras, 2012.

Além do bem e do mal. Tradução: Paulo César de Souza. São Paulo - SP: Ed. Companhia das letras, 2005.

Assim falou Zaratustra. Tradução: Paulo César de Souza. São Paulo - SP: Ed. Companhia das letras, 2011.

Crepúsculo dos ídolos. Tradução: Paulo César de Souza. São Paulo: Editora Companhia das Letras, 2010.

1995.

Da Retórica. Tradução: Tito Cardoso e Cunha. São Paulo - SP: Ed. Veja, 
Ecce homo. Como Alguém se Torna o que é. Tradução: Paulo César de Souza. São Paulo - SP

Fragmentos póstumos VI (1885 - 1887). Tradução de Marco Antônio Casanova. Rio de Janeiro - RJ: Ed. Egn/Forense Universitária, 2013.

Fragmentos póstumos VII (1887 - 1889). Rio de Janeiro - RJ: Ed. Egn/Forense Universitária, 2012.

O anticristo e Ditirambos de Dionísio. Tradução: Paulo César de Souza. São Paulo - SP: Ed. Companhia das letras, 2009.

ROUSSEAU, Jean-Jacques. Do contrato social. São Paulo - SP: Abril Cultural, 1974.

Discurso sobre a origem e os fundamentos da desigualdade entre os homens. São Paulo - SP: Abril Cultural, 1974.

SANTOS, Mario Ferreira dos. Ontologia e cosmologia: a ciência do ser e a ciência do cosmos. $3^{\text {a }}$ Ed. São Paulo - SP: Livraria e Editora Logos LTDA, 1959.

SCHOPENHAUER, Arthur. O mundo como vontade de representação. Tradução Jair Barboza. São Paulo - SP: Ed. UNESP, 2005.

VATTIMO, Gianni. Diálogo com Nietzsche. Trad. de Silvana Cobucci Leite. São Paulo: Martins Fontes, 2010. 